\title{
Health care costs associated with chronic hepatitis $C$ virus infection in Ontario, Canada: a retrospective cohort study
}

\author{
William W.L. Wong PhD, Alex Haines MSc, Karen E. Bremner BSc, Zhan Yao MSc, \\ Andrew Calzavara MSc, Nicholas Mitsakakis PhD, Jeffrey C. Kwong MD MSc, Beate Sander PhD, \\ Hla-Hla Thein MD PhD, Murray D. Krahn MD MSc
}

\section{Abstract}

Background: High-quality estimates of health care costs are required to understand the burden of illness and to inform economic models. We estimated the costs associated with hepatitis $\mathrm{C}$ virus (HCV) infection from the public payer perspective in Ontario, Canada.

\begin{abstract}
Methods: In this population-based retrospective cohort study, we identified patients aged 18-105 years diagnosed with chronic HCV infection in Ontario from 2003 to 2014 using linked administrative data. We allocated the time from diagnosis until death or the end of follow-up (Dec. 31, 2016) to 9 mutually exclusive health states using validated algorithms: no cirrhosis, no cirrhosis (RNA negative) (i.e., cured HCV infection), compensated cirrhosis, decompensated cirrhosis, hepatocellular carcinoma, both decompensated cirrhosis and hepatocellular carcinoma, liver transplantation, terminal (liver-related) and terminal (non-liver-related). We estimated direct medical costs (in 2018 Canadian dollars) per 30 days per health state and used regression models to identify predictors of the costs.
\end{abstract}

Results: We identified 48239 patients with chronic hepatitis C, of whom 30763 (63.8\%) were men and 35891 (74.4\%) were aged $30-59$ years at diagnosis. The mean 30-day costs were $\$ 798$ (95\% confidence interval [Cl] $\$ 780-\$ 816)(n=43568)$ for no cirrhosis, $\$ 661$ (95\% Cl \$630-\$692) ( $n=6422)$ for no cirrhosis (RNA negative), $\$ 1487$ (95\% Cl $\$ 1375-\$ 1599)(n=4970)$ for compensated cirrhosis, $\$ 3659$ (95\% Cl \$3279-\$4039) ( $n=3151)$ for decompensated cirrhosis, $\$ 4238$ (95\% Cl $\$ 3480-\$ 4996)(n=550)$ for hepatocellular carcinoma, $\$ 8753(95 \% \mathrm{Cl} \$ 7130-\$ 10377)(n=485)$ for both decompensated cirrhosis and hepatocellular carcinoma, $\$ 4539$ (95\% Cl \$3746-\$5333) ( $n=372$ ) for liver transplantation, \$11 202 (95\% Cl \$10 645-\$11 760) $(n=3201)$ for terminal (liver-related) and $\$ 8801$ (95\% Cl $\$ 8331-\$ 9271)(n=5278)$ for terminal (non-liver-related) health states. Comorbidity was the most significant predictor of total costs for all health states.

Interpretation: Our findings suggest that the financial burden of HCV infection is substantially higher than previously estimated in Canada. Our comprehensive, up-to-date cost estimates for clinically defined health states of HCV infection should be useful for future economic evaluations related to this disorder.

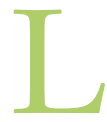

ike other developed countries, Canada agreed to meet the World Health Organization targets to reduce new cases of hepatitis $\mathrm{C}$ virus (HCV) infection by $90 \%$ and to treat $80 \%$ of eligible cases by $2030 . .^{1-3}$ Screening detects cases before symptoms develop and allows early treatment, thus potentially reducing disease burden., 4 Recently, direct-acting antivirals have transformed HCV infection treatment, offering high cure rates with improved tolerability over interferon-based treatments. ${ }^{6}$

The high costs of direct-acting antivirals initially restricted access in many jurisdictions, including Canada. ${ }^{7}$ However, time-limited agreements negotiated between Canadian provincial drug plans and pharmaceutical manufacturers allowed governments of most provinces to fully cover direct-acting antiviral treatment for all eligible patients with chronic $\mathrm{HCV}$ infection in 2018 and 2019. ${ }^{8,9}$ Economic evaluations are essential in such negotiations. Given that the current agreements may expire in 2-3 years and renegotiations will begin, accurate, up-to-date cost estimates for economic evaluations are critical for effective policy-making. ${ }^{10}$ Furthermore, estimates of the cost of illness are important for priority setting and forecasting.

Competing interests: Murray Krahn and William Wong have received research support from the Canadian Liver Foundation. No other competing interests were declared.

This article has been peer reviewed.

Correspondence to: William Wong, wwlwong@ uwaterloo.ca

CMAJ Open 2021. DOI:10.9778/cmajo.20200162 
Current costs associated with $\mathrm{HCV}$ infection are poorly understood. In a 2010 Canadian study, Krajden and colleagues ${ }^{11}$ used a 3 -phase approach (initial, late, predeath), which does not provide enough information for appropriately detailed economic evaluations. The aim of this work was to estimate health care costs for $\mathrm{HCV}$ infection health states across the clinical course of illness from diagnosis to death, and to identify predictors of those costs.

\section{Methods}

\section{Study design and setting}

We conducted a population-based retrospective analysis using administrative health data for a cohort of patients with HCV infection in Ontario, Canada. We used a health state approach, in which the natural history of disease is represented by a set of mutually exclusive and exhaustive clinical categories called health states. We defined health states using clinical events (e.g., development of hepatocellular carcinoma or liver transplantation), with a person in only 1 health state at a given time. Thus, the health state approach produces estimates that can be directly used for economic evaluation.

\section{Patient selection}

Cohort selection was based on HCV antibody and HCV RNA test results recorded in the Public Health Ontario laboratory database from Jan. 1, 2003, to Dec. 31, 2014. Public Health Ontario laboratory data were previously linked to administrative databases held at ICES using a combination of deterministic and probabilistic linkage. ${ }^{12} \mathrm{We}$ included patients aged 18-105 years with a confirmed diagnosis of chronic hepatitis C. The index date for cohort entry was the date of the first positive HCV antibody or RNA test result between 2003 and 2014.

Patients without a valid Ontario Health Insurance Plan (OHIP) number at index date and for 1 year before index date were excluded. Other exclusion criteria were missing age or sex, past infection (a negative RNA test result recorded within 12 mo of a positive antibody test result, with no record of a positive RNA test result within the previous $12 \mathrm{mo}$ ), acute infection (a negative RNA test result recorded within 12 mo of a positive RNA test result, with no Ontario Drug Benefit claims for $\mathrm{HCV}$ infection therapy within these $12 \mathrm{mo}$ ) and coinfection with HIV or hepatitis B virus.

\section{Health states}

We characterized the natural history of HCV infection using a set of relevant health states based on the literature: ${ }^{3,4,13-15}$ no cirrhosis, no cirrhosis and RNA negative (i.e., cured $\mathrm{HCV}$ infection), compensated cirrhosis, decompensated cirrhosis, hepatocellular carcinoma, both decompensated cirrhosis and hepatocellular carcinoma, liver transplantation, and 2 health states that included the 6-month period before death for patients who died, terminal (liver-related) and terminal (non-liver-related).

We defined health states from diagnostic, procedure and death codes in the administrative data, using validated algo-

rithms whenever possible. ${ }^{16}$ When this was not possible, we defined health states based on the literature or by consensus of the investigators. Health state definitions are given in Table 1 and Appendix 1, Supplemental Tables S1-S4 (available at www.cmajopen.ca/content/9/1/E167/suppl/DC1).

We identified the sequence of states experienced by each patient from index date to Dec. 31, 2016 or until death, loss of OHIP eligibility or age 106 years, whichever occurred first. Once allocated to a health state, patients remained in that state until they met the criteria for entry into another health state or the end of follow-up.

\section{Data sources and costing methods}

Our study was set in a jurisdiction with publicly paid health insurance for physician and hospital services (> 97\% of Ontarians are covered by $\mathrm{OHIP}{ }^{17,18}$ ). We took the public payer perspective and included all costs paid by the Ontario Ministry of Health. All costs were adjusted to 2018 Canadian dollars with the use of the Statistics Canada Consumer Price Index for health and personal care for Ontario. ${ }^{19}$

We obtained patient demographic data, including age, sex, residence and neighborhood income quintile, and data on

Table 1: Health state definitions and entry criteria

\begin{tabular}{|c|c|}
\hline Health state & Entry criterion/criteria \\
\hline No cirrhosis & $\begin{array}{l}\text { First date of confirmed diagnosis of } \\
\text { chronic hepatitis } \mathrm{C} \text { with positive } \mathrm{HCV} \\
\text { RNA or HCV antibody test result } \\
\text { recorded* }\end{array}$ \\
\hline $\begin{array}{l}\text { No cirrhosis (RNA } \\
\text { negative) }\end{array}$ & $\begin{array}{l}\text { Patient receives negative RNA test } \\
\text { result and has no liver disease (CC, } \\
\mathrm{DC} \text { or } \mathrm{HCC})\end{array}$ \\
\hline Compensated cirrhosis & $\begin{array}{l}\text { Patient is diagnosed with cirrhosis, or } \\
5 \text { yr before day patient is diagnosed } \\
\text { with DC† }\end{array}$ \\
\hline $\begin{array}{l}\text { Decompensated } \\
\text { cirrhosis }\end{array}$ & Patient is diagnosed with DC $\neq$ \\
\hline $\begin{array}{l}\text { Hepatocellular } \\
\text { carcinoma }\end{array}$ & Patient is diagnosed with $\mathrm{HCC} \S$ \\
\hline $\begin{array}{l}\text { Both decompensated } \\
\text { cirrhosis and } \\
\text { hepatocellular } \\
\text { carcinoma }\end{array}$ & $\begin{array}{l}\text { Patient is diagnosed with HCC while } \\
\text { already having DC diagnosis, or is } \\
\text { diagnosed with DC while already } \\
\text { having HCC diagnosis }\end{array}$ \\
\hline Liver transplantation & $\begin{array}{l}\text { Patient receives } L T \text { during } \\
\text { observation period }\end{array}$ \\
\hline Terminal, liver-related & $\begin{array}{l}6 \text { mo before day of death in patient } \\
\text { with advanced liver disease (DC, } \\
\text { HCC or LT) }\end{array}$ \\
\hline $\begin{array}{l}\text { Terminal, non-liver- } \\
\text { related }\end{array}$ & $\begin{array}{l}6 \text { mo before day of death in patient } \\
\text { without advanced liver disease }\end{array}$ \\
\hline
\end{tabular}

Note: $\mathrm{CC}=$ compensated cirrhosis, $\mathrm{DC}=$ decompensated cirrhosis, $\mathrm{HCC}=$ hepatocellular carcinoma, $\mathrm{HCV}=$ hepatitis $\mathrm{C}$ virus, $\mathrm{LR}=$ liver-related, $\mathrm{LT}=$ liver transplantation, NLR = non-liver-related.

*See Appendix 1, Supplemental Table S1 for detailed cases definition. †See Appendix 1, Supplemental Table S2 for detailed cases definition. ¥See Appendix 1, Supplemental Table S3 for detailed cases definition. §See Appendix 1, Supplemental Table S4 for detailed cases definition. 
resource use from administrative databases. ${ }^{20} \mathrm{We}$ estimated costs for health care resources using standard methods for Ontario administrative data. ${ }^{20}$ Detailed data sources and costing methods are described in Appendix 1.

\section{Statistical analysis}

We estimated mean health care costs per 30 days and their $95 \%$ confidence intervals (CIs) by cost category and health state. We used $3 \gamma$ regression models with log-link to identify predictors associated with health care costs per 30 days for health states with no advanced liver disease (no cirrhosis, no cirrhosis [RNA negative], compensated cirrhosis), advanced liver disease (decompensated cirrhosis, hepatocellular carcinoma, both decompensated cirrhosis and hepatocellular carcinoma, liver transplantation) and terminal disease (liverrelated and non-liver-related). ${ }^{21} \mathrm{We}$ used generalized estimating equations to account for within-patient correlation of longitudinal observations. For each model, we incorporated age, sex, income quintile, comorbidity (Johns Hopkins Aggregated Diagnosis Groups score accrued in the $2 \mathrm{yr}$ before the index date), immigrant status (yes/no) and prior treatment (yes/no) as predictors. Patients with missing covariate information were excluded from the regression models. SAS statistical software (SAS Institute) was used for the analyses.

To assess the effects of direct-acting antivirals on overall costs, we performed a sensitivity analysis using data only since 2012, when first-generation direct-acting antivirals became available in Ontario. ${ }^{22}$

\section{Ethics approval}

The use of data in this project was authorized under section 45 of Ontario's Personal Health Information Protection Act, which does not require review by a research ethics board.

\section{Results}

Of the 94014 patients identified with a positive HCV antibody or RNA test result, 45775 were excluded: 4679 had past infection, 1259 had acute infection, 22895 were diagnosed before 2003, and 16942 had no OHIP number, had coinfection with HIV or hepatitis B virus, or were outside the age limits. There were thus 48239 patients with chronic hepatitis C who met our criteria.

The cohort's demographic and clinical characteristics at index date (date of diagnosis) are presented in Table 2. About three-quarters of patients (35 891 [74.4\%]) were 30-59 years of age, and $30763(63.8 \%)$ were men. Most were nonimmigrants (43 315 [89.8\%]) and resided in urban (43007 [89.2\%]) and low-income (quintiles 1 and 2) (27 718 [57.5\%]) neighbourhoods. Of the 29922 patients $(62.0 \%)$ who had HCV genotype recorded, 19572 (65.4\%) were infected with genotype 1. At diagnosis, 43568 patients (90.3\%) were noncirrhotic, and 2414 (5.0\%) had compensated cirrhosis.

During follow-up, patients moved between health states when they met the entry criteria. For example, of the

\begin{tabular}{|c|c|}
\hline Characteristic & $\begin{array}{c}\text { No. (\%) of } \\
\text { patients } \\
n=48239\end{array}$ \\
\hline \multicolumn{2}{|l|}{ Age group, yr } \\
\hline $18-24$ & $2951(6.1)$ \\
\hline $25-29$ & $3438(7.1)$ \\
\hline $30-34$ & $3959(8.2)$ \\
\hline $35-39$ & $4874(10.1)$ \\
\hline $40-44$ & $6535(13.5)$ \\
\hline $45-49$ & 8007 (16.6) \\
\hline $50-54$ & $7641(15.8)$ \\
\hline $55-59$ & $4875(10.1)$ \\
\hline $60-64$ & $2266(4.7)$ \\
\hline $65-69$ & $1248(2.6)$ \\
\hline $70-74$ & $847(1.8)$ \\
\hline $75-79$ & $776(1.6)$ \\
\hline $80-84$ & $504(1.0)$ \\
\hline 85-105 & $318(0.7)$ \\
\hline \multicolumn{2}{|l|}{ Sex } \\
\hline Male & $30763(63.8)$ \\
\hline Female & $17476(36.2)$ \\
\hline \multicolumn{2}{|l|}{ Residence } \\
\hline Rural & $5087(10.5)$ \\
\hline Urban & 43007 (89.2) \\
\hline Missing & $145(0.3)$ \\
\hline \multicolumn{2}{|l|}{ Income quintile } \\
\hline Q1 (lowest) & $16957(35.2)$ \\
\hline Q2 & $10761(22.3)$ \\
\hline Q3 & $8222(17.0)$ \\
\hline Q4 & $6777(14.0)$ \\
\hline Q5 (highest) & $5030(10.4)$ \\
\hline Missing & $492(1.0)$ \\
\hline Immigrant & $4924(10.2)$ \\
\hline \multicolumn{2}{|l|}{ Hepatitis C virus genotype } \\
\hline G1 & $19572(40.6)$ \\
\hline G2 & $3468(7.2)$ \\
\hline G3 & $5898(12.2)$ \\
\hline G4 & $501(1.0)$ \\
\hline G5 & $41(0.1)$ \\
\hline G6 & $152(0.3)$ \\
\hline Mixed & $290(0.6)$ \\
\hline Missing & $18317(38.0)$ \\
\hline \multicolumn{2}{|l|}{ Health state at diagnosis } \\
\hline No cirrhosis & $43568(90.3)$ \\
\hline Compensated cirrhosis & $2414(5.0)$ \\
\hline Decompensated cirrhosis & $859(1.8)$ \\
\hline Hepatocellular carcinoma & $79(0.2)$ \\
\hline $\begin{array}{l}\text { Both decompensated cirrhosis and } \\
\text { hepatocellular carcinoma }\end{array}$ & $27(0.1)$ \\
\hline Liver transplantation & $108(0.2)$ \\
\hline Terminal, liver-related & $504(1.0)$ \\
\hline Terminal, non-liver-related & $680(1.4)$ \\
\hline \multicolumn{2}{|c|}{$\begin{array}{l}\text { Comorbidity, Aggregated Diagnosis Groups } \\
\text { score }\end{array}$} \\
\hline 0 & $1287(2.7)$ \\
\hline $1-3$ & $14321(29.7)$ \\
\hline $4-7$ & $20017(41.5)$ \\
\hline $8-10$ & $8037(16.7)$ \\
\hline$\geq 11$ & $4577(9.5)$ \\
\hline
\end{tabular}


43568 patients who entered the no cirrhosis state at diagnosis, $6422(14.7 \%)$ moved into the no cirrhosis (RNA negative) health state, and 2556 (5.9\%) moved into the cirrhosis health state. The health state membership of all patients, at diagnosis and during follow-up, is shown in Figure 1. Appendix 1, Supplemental Figure S1 illustrates the conceptual transition.

Our analysis of costs included 43568 cases of no cirrhosis, 6422 cases of no cirrhosis (RNA negative), 4970 cases of compensated cirrhosis, 3151 cases of decompensated cirrhosis, 550 cases of hepatocellular carcinoma, 485 cases of both decompensated cirrhosis and hepatocellular carcinoma, 372 cases of liver transplantation, 3201 cases of terminal (liver-related) and 5278 cases of terminal (non-liver-related) that contributed observation time to each of those health states. The average number of days in each health state was 2434 for no cirrhosis, 1919 for no cirrhosis (RNA negative), 1247 for compensated cirrhosis and 1146 for decompensated cirrhosis. The average duration of hepatocellular carcinoma was 565 days and of both decompensated cirrhosis and hepatocellular carcinoma, 524 days. The average time since liver transplantation was 1480 days.

\section{Health care costs}

The average total health care costs per 30 days increased with disease progression, from $\$ 798$ during the no cirrhosis state to $\$ 11202$ during the terminal (liver-related) state (Table 3).
The average total health care costs per 30 days in the advanced liver disease health states were high, at $\$ 3659$ for decompensated cirrhosis, $\$ 4238$ for hepatocellular carcinoma, and $\$ 8753$ for both decompensated cirrhosis and hepatocellular carcinoma. The lowest average total health care cost per 30 days was $\$ 661$ for those who achieved viral clearance (no cirrhosis [RNA negative]). The weighted average total health care cost per 30 days among all patients was $\$ 2184$.

Outpatient visits accounted for $16 \%-30 \%$ of total costs throughout the trajectory of $\mathrm{HCV}$ infection. Acute inpatient care accounted for more than $60 \%$ of costs during terminal states, compared to $15 \%$ and $22 \%$ of costs during the 2 noncirrhotic states. Outpatient prescription drugs represented $23 \%$ of costs during the no cirrhosis state and $32 \%$ of costs in the no cirrhosis (RNA negative) state, versus $14 \%$ of costs in both the decompensated cirrhosis state and the hepatocellular carcinoma state.

Our sensitivity analysis of costs from 2012 onward showed that the average total 30-day costs were $\$ 1037$ for no cirrhosis, $\$ 737$ for no cirrhosis (RNA negative), \$2732 for compensated cirrhosis, $\$ 4292$ for decompensated cirrhosis, $\$ 4670$ for hepatocellular carcinoma, $\$ 8137$ for both decompensated cirrhosis and hepatocellular carcinoma, \$6539 for liver transplantation, \$10 460 for terminal (liver-related) and \$7787 for terminal (non-liver-related) health states (Appendix 1, Supplemental Table S5). These costs were similar to the costs for

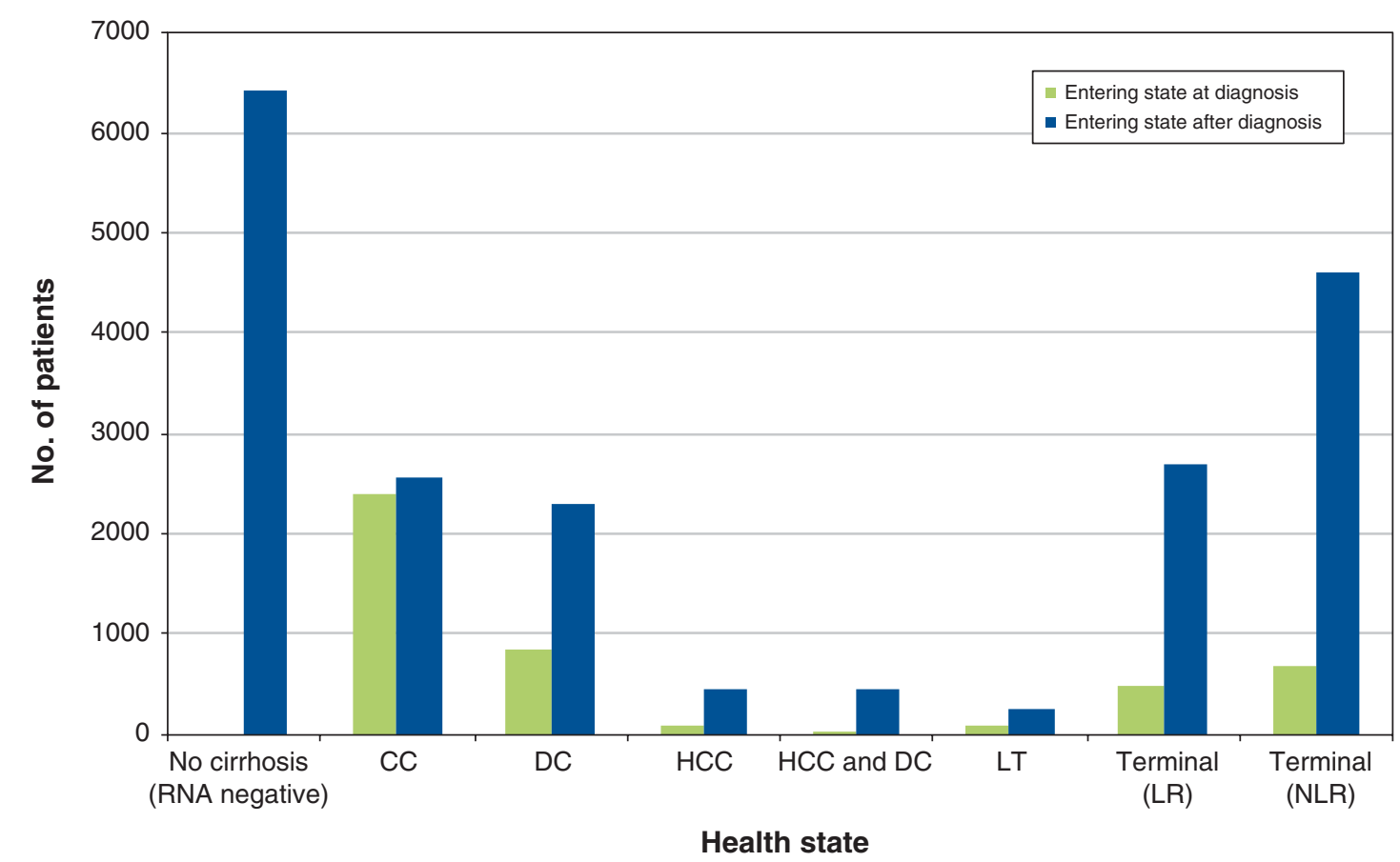

Figure 1: Overall health state membership for Ontario patients with chronic hepatitis C, 2003-2016. Not shown are the 43568 patients who entered the health state "no cirrhosis" at diagnosis. Note: CC = compensated cirrhosis, DC $=$ decompensated cirrhosis, HCC = hepatocellular carcinoma, LR = liver-related, LT = liver transplantation, NLR = non-liver-related. 


\begin{tabular}{|c|c|c|c|c|c|}
\hline \multirow[b]{2}{*}{ Cost category } & \multicolumn{5}{|c|}{ Health state; mean cost per $30 \mathrm{~d}(95 \% \mathrm{Cl}), \$$} \\
\hline & No cirrhosis & $\begin{array}{l}\text { No cirrhosis } \\
\text { (RNA negative) }\end{array}$ & Compensated cirrhosis & $\begin{array}{l}\text { Decompensated } \\
\text { cirrhosis }\end{array}$ & $\begin{array}{l}\text { Hepatocellular } \\
\text { carcinoma }\end{array}$ \\
\hline Outpatient visits & $51(50-52)$ & $44(42-46)$ & $86(79-93)$ & $198(181-215)$ & $303(256-349)$ \\
\hline Physician services & $160(157-162)$ & $151(147-155)$ & $243(227-260)$ & $599(442-755)$ & $834(711-957)$ \\
\hline $\begin{array}{l}\text { Emergency department } \\
\text { visits }\end{array}$ & $31(30-31)$ & $23(21-24)$ & $54(45-63)$ & $163(137-189)$ & $130(61-200)$ \\
\hline Same-day surgery & $12(12-13)$ & $15(14-17)$ & $37(33-42)$ & $69(58-80)$ & $36(28-44)$ \\
\hline Acute inpatient care & $175(165-185)$ & $98(86-110)$ & $470(390-551)$ & $1750(1529-1971)$ & $1907(1317-2497)$ \\
\hline $\begin{array}{l}\text { Outpatient prescription } \\
\text { medications }\end{array}$ & $187(184-191)$ & $215(204-225)$ & $390(348-431)$ & $507(457-556)$ & $609(448-770)$ \\
\hline Home care & $23(22-25)$ & $15(12-18)$ & $40(35-45)$ & $100(89-110)$ & $123(96-151)$ \\
\hline Continuing care & $23(18-27)$ & $7(1-12)$ & $30(16-45)$ & $57(37-76)$ & $33(0-69)$ \\
\hline Long-term care & $23(21-25)$ & $4(2-7)$ & $27(19-35)$ & $42(31-53)$ & $51(18-85)$ \\
\hline Other services & $114(107-121)$ & $89(72-107)$ & $109(92-127)$ & $175(125-224)$ & $212(102-223)$ \\
\hline \multirow[t]{2}{*}{ Total cost } & $798(780-816)$ & $661(630-692)$ & 1487 (1375-1599) & 3659 (3279-4039) & 4238 (3480-4996) \\
\hline & $\begin{array}{l}\text { Both decompensated } \\
\text { cirrhosis and } \\
\text { hepatocellular } \\
\text { carcinoma }\end{array}$ & $\begin{array}{c}\text { Liver } \\
\text { transplantation }\end{array}$ & Terminal, liver-related & $\begin{array}{c}\text { Terminal, } \\
\text { non-liver-related }\end{array}$ & \\
\hline Outpatient visits & $544(443-646)$ & $325(276-374)$ & $518(482-553)$ & $358(331-386)$ & \\
\hline Physician services & $1891(1422-2361)$ & $651(534-768)$ & 1401 (1327-1475) & 1076 (1004-1148) & \\
\hline $\begin{array}{l}\text { Emergency department } \\
\text { visits }\end{array}$ & $163(124-202)$ & $80(67-93)$ & 305 (290-319) & $199(188-210)$ & \\
\hline Same-day surgery & $89(45-133)$ & $96(31-161)$ & $47(42-52)$ & $28(23-33)$ & \\
\hline Acute inpatient care & 4966 (3880-6052) & 1932 (1369-2496) & 7564 (7090-8039) & $5408(5016-5800)$ & \\
\hline $\begin{array}{l}\text { Outpatient prescription } \\
\text { medications }\end{array}$ & $683(526-839)$ & 701 (604-798) & $318(280-357)$ & $332(310-355)$ & \\
\hline Home care & 215 (163-266) & $130(94-167)$ & 366 (342-389) & $293(271-316)$ & \\
\hline Continuing care & $14(0-29)$ & $102(0-220)$ & 337 (280-394) & $356(302-410)$ & \\
\hline Long-term care & $25(1-49)$ & $45(11-78)$ & $107(87-127)$ & 241 (217-265) & \\
\hline Other services & $164(91-237)$ & $477(332-621)$ & $240(196-284)$ & $509(457-561)$ & \\
\hline Total cost & 8753 (7130-10 377) & 4539 (3746-5333) & $11202(10645-11760)$ & 8801 (8331-9271) & \\
\hline
\end{tabular}

all years of the study, except that costs for the early stages were higher. Outpatient drug costs increased to $27 \%$ and $39 \%$ of total costs for the 2 noncirrhotic states. The mean total cost for compensated cirrhosis was almost twice as high in these later years as in the primary analysis. Outpatient drug costs were almost 3 times as high and represented $41 \%$ of total costs.

\section{Predictors of health care costs}

The regression models are described in Appendix 1, Supplemental Table S6. When other predictors were held constant, costs decreased significantly with increasing age in the nonadvanced liver disease states and increased with increasing age in the terminal states, but age had no significant effect in the advanced liver disease states (Table 4). Male sex was associated with $7 \%$ higher costs than female sex in the nonadvanced liver disease states but had no statistically significant effect in the other states. Patients in higher income quintiles had lower costs during the nonadvanced liver disease states but not in the later health states. Comorbidity was the strongest predictor of total health care costs across all states, with patients with 11 or more Aggregated Diagnosis Groups accruing costs up to threefold higher. In the nonadvanced and advanced disease states, immigrant status was associated with lower costs, and previous treatment for $\mathrm{HCV}$ infection was associated with higher costs. 
Table 4: Predictors of total health care costs for patients with chronic hepatitis $C$ virus infection

\begin{tabular}{|c|c|c|c|}
\hline \multirow[b]{2}{*}{ Characteristic } & \multicolumn{3}{|c|}{ Regression model; relative cost ${ }^{\star}(95 \% \mathrm{Cl})$} \\
\hline & $\begin{array}{c}\text { Nonadvanced liver } \\
\text { disease } \dagger \\
n=45539\end{array}$ & $\begin{array}{l}\text { Advanced liver } \\
\text { disease } \neq \\
n=3838\end{array}$ & $\begin{array}{l}\text { Terminal disease } \\
\quad n=8401\end{array}$ \\
\hline \multicolumn{4}{|l|}{ Age, yr } \\
\hline 20 & $1.38(1.30-1.47)$ & $0.91(0.83-1.02)$ & $0.73(0.65-0.82)$ \\
\hline 30 & $1.09(1.07-1.13)$ & $0.96(0.91-1.01)$ & $0.87(0.83-0.91)$ \\
\hline 40 & Reference & Reference & Reference \\
\hline 50 & $1.04(1.03-1.06)$ & $1.05(0.99-1.10)$ & $1.12(1.08-1.15)$ \\
\hline 60 & $1.25(1.21-1.29)$ & $1.09(0.98-1.21)$ & $1.21(1.15-1.28)$ \\
\hline 70 & $1.73(1.64-1.82)$ & $1.14(0.98-1.33)$ & $1.27(1.20-1.36)$ \\
\hline 80 & $2.73(2.51-2.98)$ & $1.19(0.97-1.47)$ & $1.30(1.20-1.41)$ \\
\hline \multicolumn{4}{|l|}{ Sex } \\
\hline Female & Reference & Reference & Reference \\
\hline Male & $1.07(1.02-1.11)$ & $1.00(0.90-1.11)$ & $0.94(0.88-1.00)$ \\
\hline \multicolumn{4}{|l|}{ Neighbourhood income quintile } \\
\hline Q1 (lowest) & Reference & Reference & Reference \\
\hline Q2 & $0.93(0.89-0.98)$ & $0.89(0.77-1.03)$ & $1.07(1.00-1.15)$ \\
\hline Q3 & $0.87(0.82-0.93)$ & $0.91(0.79-1.05)$ & $1.05(0.97-1.14)$ \\
\hline Q4 & $0.89(0.84-0.94)$ & $0.92(0.79-1.07)$ & $1.04(0.95-1.13)$ \\
\hline Q5 (highest) & $0.79(0.74-0.84)$ & $0.84(0.71-1.00)$ & $0.98(0.89-1.09)$ \\
\hline \multicolumn{4}{|l|}{ Measures of comorbidity } \\
\hline \multicolumn{4}{|c|}{ Aggregated Diagnosis Groups score } \\
\hline $0-3$ & $0.64(0.62-0.68)$ & $1.06(0.90-1.25)$ & $0.75(0.69-0.82)$ \\
\hline $4-7$ & Reference & Reference & Reference \\
\hline $8-10$ & $1.64(1.56-1.72)$ & $1.29(1.13-1.47)$ & $1.48(1.37-1.59)$ \\
\hline$\geq 11$ & $3.44(3.24-3.65)$ & $1.79(1.58-2.02)$ & $2.10(1.95-2.25)$ \\
\hline \multicolumn{4}{|l|}{ Immigrant } \\
\hline No & Reference & Reference & Reference \\
\hline Yes & $0.62(0.57-0.67)$ & $0.79(0.68-0.93)$ & $1.19(1.06-1.34)$ \\
\hline \multicolumn{4}{|c|}{ Hepatitis $C$ virus infection treatment } \\
\hline No & Reference & Reference & Reference \\
\hline Yes & $2.65(2.56-2.74)$ & $1.78(1.62-1.97)$ & $1.07(0.83-1.37)$ \\
\hline \multicolumn{4}{|l|}{ Health state } \\
\hline No cirrhosis & $1.10(1.04-1.16)$ & - & - \\
\hline No cirrhosis (RNA negative) & Reference & - & - \\
\hline Compensated cirrhosis & $1.53(1.41-1.66)$ & - & - \\
\hline Decompensated cirrhosis & - & Reference & - \\
\hline Hepatocellular carcinoma & - & $1.10(0.94-1.28)$ & - \\
\hline $\begin{array}{l}\text { Both decompensated } \\
\text { cirrhosis and hepatocellular } \\
\text { carcinoma }\end{array}$ & - & $1.69(1.45-1.97)$ & - \\
\hline Liver transplantation & - & $1.12(0.96-1.31)$ & - \\
\hline Terminal, non-liver-related & - & - & Reference \\
\hline Terminal, liver-related & - & - & $1.24(1.17-1.32)$ \\
\hline \multicolumn{4}{|c|}{$\begin{array}{l}\text { Note: } \mathrm{Cl}=\text { confidence interval. } \\
{ }^{*} \text { Calculated by taking exp }(B) \text {, where } B \text { is the coefficient in the multiple regression predicting log-transformed cost. Relative cost for any } \\
\text { category represents the proportion by which mean cost is increased relative to the referent category, all other variables being held constant } \\
\text { tIncludes health states of no cirrosis, no cirrhosis (RNA negative) and compensated cirrhosis. } \\
\text { †lncludes health states of decompensated cirrhosis, hepatocellular carcinoma, both decompensated cirrhosis and hepatocellular } \\
\text { carcinoma, and liver transplantation. } \\
\text { §Includes health states of terminal (non-liver-related) and terminal (liver-related). }\end{array}$} \\
\hline
\end{tabular}




\section{Interpretation}

The 2010 Ontario Burden of Infectious Disease Study suggested that HCV infection had the highest health burden of any infectious disease in Ontario in terms of health-adjusted life years..$^{23}$ Our findings suggest that the financial burden of HCV infection is also high. Costs increased with severity of disease and were highest at the end of life (\$8801 and \$11 202 per $30 \mathrm{~d}$ for terminal non-liver-related and liver-related health states, respectively). We found that age, sex, immigrant status, previous treatment and especially comorbid illness were important predictors of health care costs. Costs for acute inpatient services were high in all health states and increased with disease progression. Costs for late-stage complications of chronic hepatitis $\mathrm{C}$, including decompensated cirrhosis and liver transplantation, were very high. For example, our mean 30 -day cost for decompensated cirrhosis, $\$ 3659$, is similar to the initial-phase 30-day costs for the 4 most common cancers (breast, colorectal, lung and prostate), \$1825-\$5236 (2018 Canadian dollars) ${ }^{24}$ and is much higher than the average 30-day cost for acute myocardial infarction, \$452 (2018 Canadian dollars). ${ }^{25}$

Our findings suggest that the financial burden of HCV infection is substantially higher than previously estimated in Canada. Krajden and colleagues, ${ }^{11}$ using data for British Columbia, estimated the total health care costs per 30 days to be $\$ 320$ (2005 Canadian dollars) for early-stage HCV infection and \$904 (2005 Canadian dollars) for late-stage HCV infection (including hepatocellular carcinoma, decompensated cirrhosis and compensated cirrhosis). After adjustment for inflation, ${ }^{26}$ our cost estimate for no cirrhosis is almost twice their estimate (\$798 v. \$386), and our estimates for late-stage disease are at least 37\% higher (ranging from $\$ 1487$ for compensated cirrhosis to $\$ 8753$ for both decompensated cirrhosis and hepatocellular carcinoma v. \$1088). The differences may be due to different costing methods or care patterns, or updated treatments.

In a study in the United States, McAdam-Marx and colleagues ${ }^{27}$ estimated the total 30-day health care costs of HCVrelated compensated cirrhosis, decompensated cirrhosis and hepatocellular carcinoma in 2010 to be US\$1387, US\$3439 and US\$4807, respectively. When converted to 2018 Canadian dollars, these costs are congruent with ours $(\$ 1852 \mathrm{v}$. $\$ 1487, \$ 4593$ v. \$3659 and \$6420 v. \$4238, respectively). ${ }^{27}$ In a study in France, the 30-day costs for a hospital stay for HCV-related compensated cirrhosis, decompensated cirrhosis and hepatocellular carcinoma in 2010 were estimated to be $€ 316$, €1028 and €1149, respectively (\$494, \$1608 and \$1797, respectively, in 2018 Canadian dollars). ${ }^{28}$

\section{Limitations}

Our study has several strengths. Because Ontario has publicly paid health insurance for physician and hospital services, and more than $97 \%$ of Ontarians are covered under OHIP, ${ }^{17,18}$ we were able to capture use of almost all publicly funded health care services, by resource type. Although our cohort may not have included all asymptomatic patients with chronic HCV infection, it included all diagnosed cases of $\mathrm{HCV}$ infection in Ontario from 2003 to 2014. We defined health states in more detail than Krajden and colleagues. ${ }^{11}$ Our approach is arguably more clinically meaningful and is more suitable for economic evaluations; most modelling studies ${ }^{3,4,13}$ include similarly defined health states. ${ }^{29}$

Limitations of our study include that we excluded patients without valid OHIP numbers, and chronic hepatitis C disproportionately affects socioeconomically marginalized populations, ${ }^{30}$ who may not have a permanent address from which to apply for publicly funded health insurance. We could not include costs borne by private health insurers or, more important, out-of-pocket costs paid by patients, many of whom are unable to work because of HCV infection. Patients who are not covered by the Ontario Drug Benefit program must pay for outpatient drugs, including antiviral therapy, out of pocket or through private insurance. Furthermore, our analysis was not able to distinguish between liver-related and non-liverrelated costs. Thus, our results may over- or underestimate the economic burden of $\mathrm{HCV}$ infection.

Last, owing to data availability, we captured diagnostic information only to December 2014 and follow-up information to December 2016. Thus, our estimates do not fully capture recent screening recommendations and the use of the interferon-free direct-acting antivirals, which were approved for use in Canada in December 2014.22 Our sensitivity analysis using data as of the approval of first-generation directacting antivirals (in 2012) onward ${ }^{22}$ indicated that total health care costs for the noncirrhotic and compensated cirrhosis health states were higher during this later era than in earlier years, and outpatient drug costs accounted for higher proportions of total costs. Further analysis will be necessary when more data become available.

\section{Conclusion}

Our findings suggest that the financial burden of HCV infection is substantially higher than previously estimated in Canada. Our robust, comprehensive, up-to-date cost estimates for clinically defined health states of HCV infection should be useful for economic evaluations and to estimate the burden of illness for setting priorities, making decisions about reimbursement and forecasting costs. Although our results are most relevant to Ontario, the comprehensiveness of our study should allow analysts in other settings to understand relative costs across disease stages, including end-of-life costs, and the implications of age, sex, and particularly comorbid illness as predictors of total costs. Improving the quality of costing should strengthen the evidence basis of efforts to eliminate $\mathrm{HCV}$ infection in Canada and internationally.

\section{References}

1. Combating hepatitis $B$ and $C$ to reach elimination by 2030: advocacy brief. Geneva: World Health Organization; 2016.

2. Fish S, Dickie M. Global health sector strategy on viral hepatitis: What does it mean for Canadians? Toronto: Canadian AIDS Treatment Information Exchange; 2018.

3. Wong WWL, Erman A, Feld JJ, et al. Model-based projection of health and economic effects of screening for hepatitis C in Canada. CMA7 Open 2017;5: E662-72. 
4. Wong WWL, Tu HA, Feld JJ, et al. Cost-effectiveness of screening for hepatitis C in Canada. CMA7 2015;187:E110-21.

5. Shah HA, Heathcote J, Feld JJ. A Canadian screening program for hepatitis C: Is now the time? CMA7 2013;185:1325-8.

6. Shah H, Bilodeau M, Burak KW et al.; for the Canadian Association for the Study of the Liver. The management of chronic hepatitis C: 2018 guideline update from the Canadian Association for the Study of the Liver. CMA7 2018; 190:E677-87.

7. Marshall AD, Saeed S, Barrett L, et al. Canadian Network on Hepatitis C (CanHepC). Restrictions for reimbursement of direct-acting antiviral treatment for hepatitis $\mathrm{C}$ virus infection in Canada: a descriptive study. CMA7 Open 2016;4:E605-14.

8. British Columbia PharmaCare lists AbbVie's hepatitis $\mathrm{C}$ treatment MAVIRETT $^{\mathrm{TM}}$ on its formulary [news release]. North Chicago: AbbVie; 2019 Mar. 22. Available: www.newswire.ca/news-releases/british-columbia -pharmacare-lists-abbvie-s-hepatitis-c-treatment-maviret-tm-on-its-formulary -821046766.html (accessed 2019 Oct. 3).

9. A statement from the pan-Canadian Pharmaceutical Alliance. Cision; 2017 Feb. 21. Available: https://www.newswire.ca/news-releases/a-statement-from -the-pan-canadian-pharmaceutical-alliance-614373463.html (accessed 2019 Oct. 3).

10. Technology and market landscape: hepatitis C medicines. Geneva: World Health Organization; 2017. Available: https://unitaid.org/assets/HCV -Medicines-Landscape_Aug-2017.pdf (accessed 2020 Feb. 2).

11. Krajden M, Kuo M, Zagorski B, et al. Health care costs associated with hepatitis C: a longitudinal cohort study. Can $\mathcal{F}$ Gastroenterol 2010;24:717-26.

12. Yasseen AS 3rd. Viral hepatitis among immigrants: a population-based comparison using linked laboratory and health administrative data [thesis]. Toronto: University of Toronto; 2020.

13. Wong WWL, Lee KM, Singh S, et al. Drug therapies for chronic hepatitis $\mathrm{C}$ infection: a cost-effectiveness analysis. CMAF Open 2017;5:E97-108.

14. Coward S, Leggett L, Kaplan GG, et al. Cost-effectiveness of screening for hepatitis C virus: a systematic review of economic evaluations. BMF Open 2016; 6:e011821.

15. Chhatwal J, He T, Lopez-Olivo MA. Systematic review of modelling approaches for the cost effectiveness of hepatitis $\mathrm{C}$ treatment with direct-acting antivirals. Pharmacoeconomics 2016;34:551-67.

16. Lapointe-Shaw L, Georgie F, Carlone D, et al. Identifying cirrhosis, decompensated cirrhosis and hepatocellular carcinoma in health administrative data: a validation study. PLoS One 2018;13:e0201120.

17. Rousseau C, Laurin-Lamothe A, Rummens JA, et al. Uninsured immigrant and refugee children presenting to Canadian paediatric emergency departments: disparities in help-seeking and service delivery. Paediatr Child Health 2013;18:465-9.

18. Hynie M, Ardern CI, Robertson A. Emergency room visits by uninsured child and adult residents in Ontario, Canada: what diagnoses, severity and visit disposition reveal about the impact of being uninsured. 7 Immigr Minor Health 2016;18:948-56.

19. Table 18-10-0005-01: Consumer Price Index, annual average, not seasonally adjusted. Ottawa: Statistics Canada. Available: www150.statcan.gc.ca/t1/tbl1/ en/tv.action?pid=1810000501 (accessed 2020 Feb. 5).

20. Wodchis WP, Bushmeneva K, Nikitovic M, et al. Guidelines on person-level costing using administrative databases in Ontario. Health System Performance Research Network; 2013.

21. Austin PC, Ghali WA, Tu JV. A comparison of several regression models for analysing cost of CABG surgery. Stat Med 2003;22:2799-815.

22. Myers RP, Shah H, Burak KW, et al. An update on the management of chronic hepatitis C: 2015 Consensus guidelines from the Canadian Association for the Study of the Liver. Can 7 Gastroenterol Hepatol 2015;29:19-34.

23. Kwong JC, Crowcroft NS, Campitelli MS, et al.; Ontario Burden of Infectious Disease Study Advisory Group. Ontario Burden of Infectious Disease Study. Toronto: Ontario Agency for Health Protection and Promotion/ICES; 2010.

24. De Oliveira C, Pataky R, Bremner KE, et al. Estimating the cost of cancer care in British Columbia and Ontario: a Canadian inter-provincial comparison. Healthc Policy 2017;12:95-108.

25. Cohen D, Manuel DG, Tugwell P, et al. Direct healthcare costs of acute myocardial infarction in Canada's elderly across the continuum of care. 7 Econ Ageing 2014;3:44-9.

26. Table 18-10-0005-01. Consumer Price Index, monthly, percentage change, not seasonally adjusted. Ottawa: Statistics Canada. Available: www150.statcan.gc.ca/t1/ tbl1/en/tv.action?pid=1810000501 (accessed 2019 Nov. 30).

27. McAdam-Marx C, McGarry LJ, Hane CA, et al. All-cause and incremental per patient per year cost associated with chronic hepatitis $\mathrm{C}$ virus and associated liver complications in the United States: a managed care perspective. 7 Manag Care Pharm 2011;17:531-46.

28. Schwarzinger M, Deuffic-Burban S, Mallet V, et al. Lifetime costs attributable to chronic hepatitis $\mathrm{C}$ from the French healthcare perspective [abstract]. 7 Hepatol 2013;58:S21-2.
29. Roberts M, Russell LB, Paltiel AD, et al. Conceptualizing a model: a report of the ISPOR-SMDM Modeling Good Research Practices Task Force - 2 . Value Health 2012;15:804-11.

30. Edmunds BL, Miller ER, Tsourtos G. The distribution and socioeconomic burden of hepatitis C virus in South Australia: a cross-sectional study 2010 2016. BMC Public Health 2019;19:527.

Affiliations: School of Pharmacy (Wong), University of Waterloo, Kitchener, Ont.; Toronto Health Economics and Technology Assessment Collaborative (Wong, Haines, Bremner, Sander, Thein, Krahn), University Health Network; ICES Central (Wong, Yao, Calzavara, Kwong, Sander); Dalla Lana School of Public Health (Mitsakakis, Kwong, Sander, Thein) and Department of Family and Community Medicine (Kwong), University of Toronto; Public Health Ontario (Kwong, Sander), Toronto, Ont.

Contributors: William Wong and Murray Krahn conceived the study. Hla-Hla Thein and Murray Krahn designed the study. Alex Haines, Karen Bremner, Zhan Yao and Andrew Calzavara acquired the data. William Wong, Nicholas Mitsakakis, Hla-Hla Thein and Murray Krahn analyzed the data. William Wong, Alex Haines, Karen Bremner, William Kwong, Beate Sander, Nicholas Mitsakakis, Hla-Hla Thein and Murray Krahn interpreted the data. William Wong, Alex Haines and Karen Bremner drafted the manuscript. All of the authors revised the manuscript critically for important intellectual content, approved the final version to be published and agreed to be accountable for all aspects of the work.

Funding: Funding for this study was provided by the Canadian Liver Foundation and grant MOP 137015 from the Canadian Institutes of Health Research (CIHR). William Wong's research program was supported by an Ontario Ministry of Research, Innovation and Science early researcher award, the Natural Sciences and Engineering Research Council and CIHR. Beate Sander and Murray Krahn are supported by Canada Research Chairs. This study was also supported by ICES, which is funded by an annual grant from the Ontario Ministry of Health.

Data sharing: The data set from this study is held securely in coded form at ICES. Although data-sharing agreements prohibit ICES from making the data set publicly available, access may be granted to those who meet prespecified criteria for confidential access, available at https://www.ices. on.ca/DAS. The full data set creation plan and underlying analytic code are available from the authors on request, with the understanding that the computer programs may rely on coding templates or macros that are unique to ICES and are therefore either inaccessible or may require modification.

Content licence: This is an Open Access article distributed in accordance with the terms of the Creative Commons Attribution (CC BY-NCND 4.0) licence, which permits use, distribution and reproduction in any medium, provided that the original publication is properly cited, the use is noncommercial (i.e., research or educational use), and no modifications or adaptations are made. See: https://creativecommons.org/licenses/ by-nc-nd/4.0/.

Disclaimer: This study was supported by ICES, which is funded by an annual grant from the Ontario Ministry of Health (MOH). The opinions, results and conclusions reported in this article are those of the authors and are independent from the funding sources. No endorsement by ICES or the Ontario MOH is intended or should be inferred. None of the funding organizations or sponsors had any role in the design of the study, management, analysis or interpretation of the data, or the preparation, review or approval of the manuscript. Parts of this material are based on data or information compiled and provided by the Canadian Institute for Health Information (CIHI) and Cancer Care Ontario (CCO). However, the analyses, conclusions, opinions and statements expressed herein are those of the authors and not necessarily those of CIHI or CCO. No endorsement by $\mathrm{CIHI}$ or $\mathrm{CCO}$ is intended or should be inferred.

Supplemental information: For reviewer comments and the original submission of this manuscript, please see www.cmajopen.ca/content/9/1/ E167/suppl/DC1. 